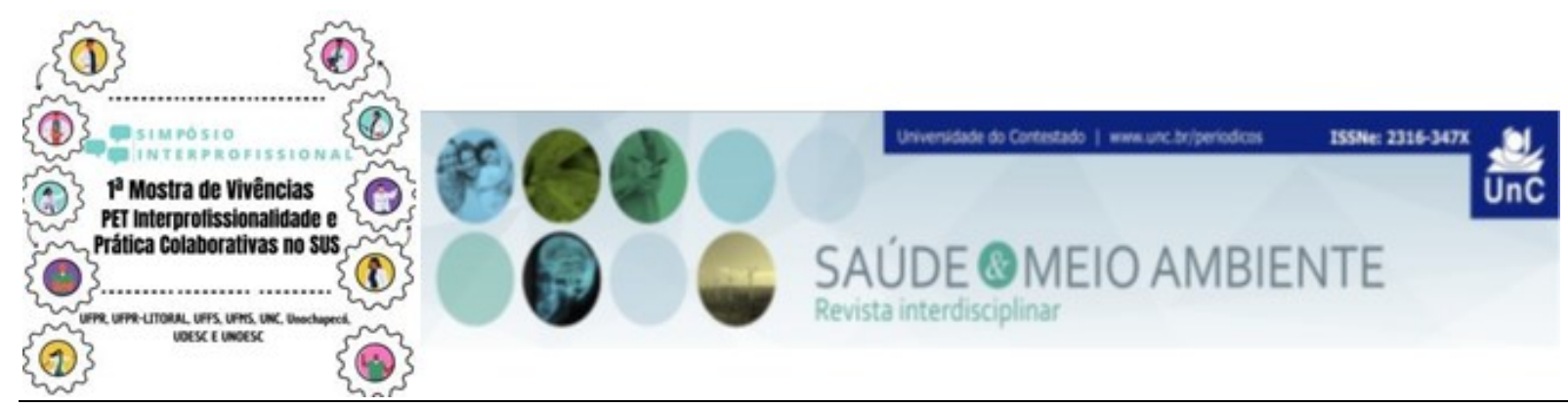

\title{
APLICAÇÃO DA METODOLOGIA DA PROBLEMATIZAÇÃO COM ARCO DE MAGUEREZ NA FORMAÇÃO INTERPROFISSIONAL POR MEIO DE TECNOLOGIAS DE INFORMAÇÃO ${ }^{1}$
}

Projeto 61

\author{
Ana Maria Farias Ribeiro ${ }^{2}$ \\ Giulia Rita Barbosa Scorsin ${ }^{3}$ \\ Merillyn Anne de Oliveira Ferro Ravaze ${ }^{4}$ \\ Rayanne Souza Donato ${ }^{5}$ \\ Liliane Patricia Plentz ${ }^{6}$ \\ Tatiana Carvalho Reis Martins ${ }^{7}$ \\ Juliana Dias Reis Pessalacia ${ }^{8}$
}

\begin{abstract}
RESUMO
Introdução: Devido ao cenário atual de pandemia de COVID-19, o Programa de Educação pelo Trabalho para a Saúde (PET Saúde/Interprofissionalidade) adaptou suas atividades por meio do uso das Tecnologias de Informação e Comunicação (TICs), visando a não interrupção das discussões voltadas para a Educação Interprofissional (EIP) e as Práticas Interprofissionais Colaborativas (PIC). Objetivo: Relatar as experiências dos acadêmicos da área de saúde, membros do PET, em uma atividade de simulação de atendimento interprofissional. Metodologia: Trata-se de um relato de experiência de acadêmicos da área de saúde, na construção de um caso a partir de discussões envolvendo um dos grupos PET Saúde. O caso foi exposto e debatido em uma reunião síncrona por Google Meet com a participação de todos membros do PET-Saúde/Interprofissionalidade de Três Lagoas/MS. Em seguida, foi analisado com a aplicação da metodologia de problematização com Arco de Maguerez

${ }^{1}$ Fonte de financiamento: Programa de Educação pelo Trabalho para a Saúde - PET

Saúde/Interprofissionalidade 2019-2021 (Edital no 10 de 23 de julho de 2018, Ministério da

Saúde/Secretaria de Gestão do Trabalho e da Educação na Saúde).

${ }^{2}$ Aluna voluntária. Graduanda em medicina pela Universidade Federal de Mato Grosso do Sul. Mato

Grosso do Sul. Brasil. E-mail: anamaria.farias1501@gmail.com

${ }^{3}$ Aluna bolsista. Graduanda em Medicina pela Universidade Federal de Mato Grosso do Sul. Mato

Grosso do Sul. Brasil. E-mail: giuliarbscorsin@gmail.com

${ }^{4}$ Aluna bolsista. Graduanda em Enfermagem pela Universidade Federal de Mato Grosso do Sul. Mato

Grosso do Sul. Brasil. E-mail: merillynanne@hotmail.com

${ }^{5}$ Aluna voluntária. Graduanda em medicina pela Universidade Federal de Mato Grosso do Sul. Mato

Grosso do Sul. Brasil. E-mail: rayannedonato@hotmail.com

${ }^{6}$ Tutora. Faculdades Integradas de Três Lagoas- AEMS. Mato Grosso do Sul. Brasil. E-mail: liliane plentz@hotmail.com

${ }^{7}$ Tutora. Universidade Federal de Mato Grosso do Sul. Mato Grosso do Sul. Brasil. E-mail: tatycnn@hotmail.com

8 Tutora. Universidade Federal de Mato Grosso do Sul. Mato Grosso do Sul. Brasil. E-mail: juliana@pessalacia.com.br
\end{abstract}

Saúde Meio Ambient. 9(Supl 1): 25-26, dez. 2020

ISSNe 2316-347X 
por meio de TIC. A atividade de simulação utilizou como base a Teoria Construtivista de Jean Piaget, e como método norteador a Aprendizagem Baseada em Problema (ABP). Resultados: A equipe propôs um caso simulado de atendimento a um imigrante haitiano, o qual envolveu em sua discussão questões de fertilidade, interprofissionalidade e culturalidade ${ }^{1}$. Por meio do Arco de Charles Maguerez buscou-se a problematização do caso, de maneira crítica e reflexiva, desenvolvidas em cinco etapas: observação da realidade, pontos-chave, teorização, hipóteses de solução e aplicação da realidade ${ }^{2}$. Essa ferramenta permite que por meio de análise sob múltiplas perspectivas, o acadêmico consiga extrair e reconhecer os problemas existentes, e assim buscar soluções. Dessa forma, a observação ativa da realidade permitiu que os discentes pudessem analisar o caso simulado de forma semelhante ao que acontece na prática acadêmica, e a observação dos pontos chaves promoveu a aplicação da interprofissionalidade no contexto do atendimento ao paciente, observando as vulnerabilidades da atenção à saúde e promovendo uma integração entre os profissionais de saúde. Já a teorização foi realizada com todo o grupo do PET-Saúde Interprofissionalidade, de forma que a problematização fosse estendida a todos os indivíduos inseridos no Programa, a fim de tornar as hipóteses de solução mais claras. Sendo assim, a aplicação à realidade se tornará mais efetiva, de forma que a simulação de caso possa servir de base para a tomada de decisões referentes ao cuidado dos pacientes posteriormente. Considerações Finais: Conclui-se que o uso dessas metodologias na construção do conhecimento, por meio das TICs, revelase como uma estratégia pedagógica eficiente e facilitadora do processo ensinoaprendizagem sobre a EIP e a PIC.

Palavras-chave: Aprendizagem Baseada em Problemas. Educação Interprofissional. Educação a Distância. Tecnologia da Informação. COVID-19.

\section{REFERÊNCIAS}

1 Faqueti A, Grisotti M, Risson AP. Saúde de imigrantes haitianos: revisão de estudos empíricos qualitativos. Interface (Botucatu). 2020 [cited 2020 Aug 27] ; 24. Available from: http://dx.doi.org/10.1590/interface.190311.

2 Do Prado ML, et al. Arco de Charles Maguerez: refletindo estratégias de metodologia ativa na formação de profissionais de saúde. Escola Anna Nery. 2012 Mar. [cited 2020 Aug 27];16 Available from: DOI: https://doi.org.10.1590/S1414$\underline{81452012000100023 .}$. 